NBER WORKING PAPER SERIES

\title{
COMPONENTS OF MANUFACTURING INVENTORIES
}

\author{
Alan J. Auerbach \\ Jerry R. Green \\ Working Paper No. 491 \\ NATIONAL BUREAU OF ECONOMIC RESEARCH \\ 1050 Massachusetts Avenue \\ Cambridge MA 02138 \\ June 1980
}

The authors would like to thank Richard Clarke for several helpful discussions, and Thomas Sargent, who was the discussant of an earlier version. The research reported here is part of the NBER's research program in Economic Fluctuations. Any opinions expressed are those of the authors and not those of the National Bureau of Economic Research. 


\section{Companents of Manufacturing Inventories}

\section{ABSTRACT}

This paper presents a structural model of production and inventory accumulation based on the hypothesis of cost minimization. It differs from previous attempts in several respects. First, it integrates the analysis of input inventories with output inventories, treating the two stocks separately. Second, it distinguishes between temporary and permanent fluctuations in sales as they are anticlpated by the industry. Third, it allows for a more general structure of adjustment costs, and in particular for a cost changing the production level rather than only for deviations of the production level from a fixed target.

Empirically, there are three principal conclusions. This model performs much better than those with no cost of production adjustment allowed. Disaggregation of inventories provides significant insights into the dynamics of the adjustment process. However, the restrictions on our model implied by the continuous-time stochastic control theory that we utilize are rejected by the data. We believe that a more disaggregated specification or a more detailed econometric treatment of the discrete-time nature of the observations would avoid this difficulty. 


\section{Introduction}

Investment in inventories is central to most theories of aggregate economic fluctuations, even though it comprises a very small part of total output. In the U.S., on average, on 1 y $0.7 \%$ of GNP is devoted to this use. Nevertheless its crucial role in the business cycle is apparent from the fact that it accounts for over $18 \%$ of the standard deviation of output growth since 1947. *

Inventory investment has proved to be very difficult to satisfactorily explain. Most theoretical work, following the justifiably celebrated paper by Metzler (1941), assumed that inventories were homogeneous and simply held for resale. Part of the difficulty with studying the complex roles of inventories in the economy may be that there is a great heterogeneity in the components of aggregate inventory investment. Input inventories are different from output inventories; and different industries have characteristically different responses of inventories to exogenous shocks.

Although there have been several excellent empirical studies of inventory behavior by type of inventory and by industry ${ }^{* *}$, most econometric work has also followed Metzler. Either all types of inventories were lumped together for purposes of estimation, or only finished goods inventories were considered. In fact, more than two thirds of the inventory by U.S. manufacturers is in materials and supplies or work in process, not finished goods. A further

$\star$

This is based on data from 1947-1979. We took the ratio of the standard deviation in the first differences of real GNP minus the first differences of inventory investment, to the standard deviation of the former series alone. **

See Abromovitz (1950) and Mack (1967). 
disturbing omission is the role of unfilled orders as "negative inventories," which is of great importance in durable goods manufacturing. In durable goods manufacturing unfilled orders are on average, about four times the finished goods inventories.

In recent years, macroeconomicshas emphasized the roles of expectations formation and optimization by economic agents. Inventories have been reconsidered from this point of view. However, as in the microeconomic analyses mentioned above, the heterogeneity of inventories by stage of fabrication has not been considered. We believe that our understanding of the role of manufacturing inventories in economic fluctuations will benefit from such a disaggregated approach in an optimizing framework.

In this paper we attempt to give a theoretical model of inventory holding based on cost minimizing behavior. Our goal is to allow for a variety of costs in the theoretical model and to see which of these are empirically important. We also want to study the interaction between inventories at different stages of fabrication and to see whether these decisions are interrelated as the theory predicts.

Our principal empirical results are two-fold: First, we find strong evidence for costs of variable production rates; that is costs of changing the rate of production, as opposed to costs of operating steadily above minimum average cost. Second we find significant evidence, though somewhat weaker, for the interaction between inventories at different stages of fabrication. Both of these phenomena have, to our knowledge, received little mention and no empirical analysis previously.

* In 1976 inventories of finished products in durable goods industries were. $\$ 22.5$ billion while unfilled orders, deflated by the wholesale price index for durable manufactured products were $\$ 91.2$ billion.

** See Blinder-Fischer (1979). 
Our model is similar to most previous work in assuming that sales are exogenous. Inventory holders develop expectations about the future time pattern of demand. One of our secondary goals was to use the statistical characteristics of the innovations in the sales process in the behavioral model. Specifically, increases in demand that are perceived as temporary may evoke much different responses than those perceived as permanent.

The contrast between temporary and permanent sales fluctuations can be seen most easily by considering two industries with identical cost structures and facing random sales with different time series characteristics. Industry A experiences primarily temporary variations in sales while in industry $B$, the variations are longer-lived, inducing the same overall variance. Suppose there is an excess of sales beyond the expected. Industry A can meet the demand out of stocks and, gradually make up for this shortfall with only a slight increase in production. There is relatively little risk that such a gradual response will find the industry with its stocks running dangerously low. Irdustry $B_{9}$, on the other hand, must respond more drastically to sales variation since it is a signal of stronger demand in the future. How would an outside observer know that the different responses of firms $A$ and $B$ stem from the differences in their sales expectations rather than from lower adjustment costs in industry $B$ than in industry $A$ ?

The remainder of the paper is organized as follows: Our data is described in Section 2. Section 3 gives a brief overview of the methodology and sets up the basic framework of both the construction of the model and Its implementation. The nature of the costs faced by firms is described In Section 4. Section 5 applies the theory of optimal control to the cost minimization problem under conditions of certainty. Since this method utilizes the principal of first-period certainty equivalence, the stochastic 
structure of the model and its relation to the data are discussed separately, in Section 6. In Sections 7 and 8 we derive the optimal controls explicitly, for two different specifications of costs, in terms of the underlying parameters. Section 9 contains a description of the implementation of these methods and the empirical results. 


\section{The Data}

Much of the shortcomings in earlier empirical work may be traced to problems in the available data. Until recently, the only manufacturing inventory data avallable by stage-of-fabrication was measured at book value. But this book value data is practically meaningless. Rapid price increases and the resulting changes in accounting method from FIFO (first-in, first-out) to LIFO (last-in, first-out) in an attempt to avoid taxation of 1llusory inventory profits, cause severe distortions. However, recent work by the Bureau of Economic Analysis has provided corrected, constant dollar inventories, by stage of fabrication, for durables and nondurables manufacturers, at the two-digit SIC level. Given this data, which extends from the last quarter of 1958 to the end of 1976, there is some hope of implementing theoretical models of heterogeneous inventory investment.

While data is available for many two-digit industries, we have chosen to study only four of them. We limit ous sample because the other industries were obviously at variance with the theoretical model we posit, or had obviously erroneous data. First, although we consider the stock-order distinction to be an important part of inventory behavior, our model cannot accomodate unfilled orders. We thus are compelled to drop industries maintaining unfilled orders. Of thos industries which produce chiefly or entirely. to stock, only two (Stone, Clay and Glass - SIC \#32, and Instruments - SIC \#38) are durables manufacturers.

Second, we were forced to omit two other industries for specific reasons concerning the data. Tobacco (SIC $\#_{21}$ ) has very little finished goods or work-in-process inventories which together compose only $8 \%$ of total inventories. 
Given the special nature of tobacco products, it is questionable whether the remaining $92 \%$, which probably consists mainly of aging tobacco leaves, should really be classified as materials and supplies. The other industry omitted here is Petroleum (SIC 非29) which, for some unknown reason, possesses (according to our data) large but essentially constant work-in-process inventories. Our inability to determine the reason for this has led to the omission of this industry.

The remaining seven industries were all suitable candidate for study. Computational difficulties (described below) made it infeasible to consider three of the seven industries ${ }^{*}$ whose detrended sales series were not best described by either an ARMA $(1,1)$ or a pure Markov process.

The remaining four industries are Food (SIC $\$ 20)$, Chemicals (SIC $i 28$ ), Rubber and Plastics (SIC $\# 30$ ) and Stone, Clay and Glass (SIC $\# 32$ ). Stone, Clay and Glass is the only durable goods industry of the four. Table 1 presents relevant summary statistics for these industries for the sample period. Though these industries differ markedly in the types of products they produce, their inventory-sales ratios and composition of total inventory stock are rather similar. One other result worth pausing to contemplate is the size of the standard deviation of inventory investment relative to average sales -about one percent. While this does not imply that inventory investment is unimportant, it does suggest a fallacy in the image one may get from the literature, of wildly fluctuating buffer stocks.

* These were Textiles (SIC \#22), Paper (SIC \#26), and Instruments (SIC \#38). See section 9 for the details of this construction.

** On this point, see the similar conclusions reached by Auerbach-Feldstein (1976). 
Table 1

Industrial Data

(in billions of $72 \$$ )

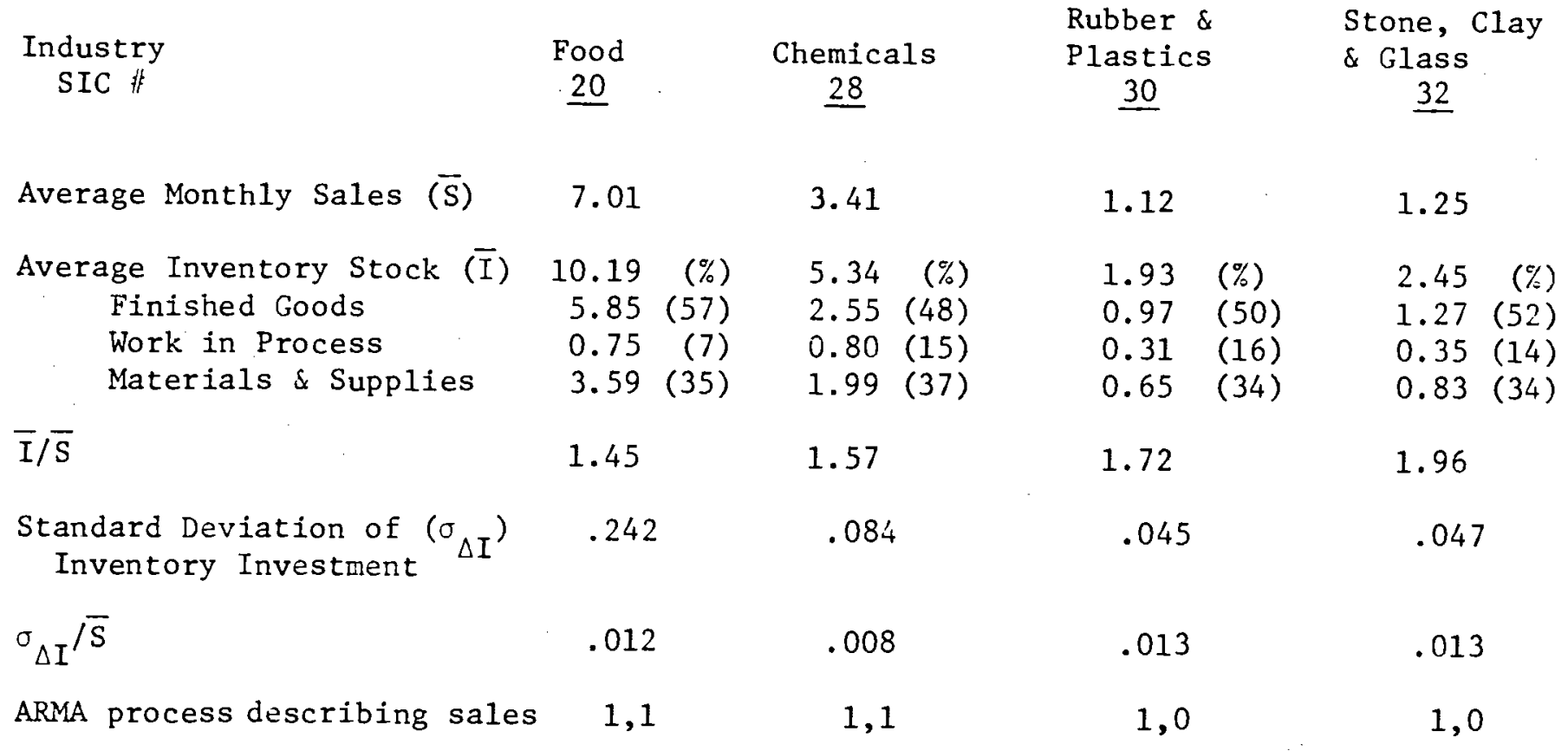

Notes

Percentages may not add to 100 due to rounding.

$\sigma_{\Delta I} / \bar{S}$ is ratio of standard deviation of quarterly inventory investment to quarterly sales. 


\section{Basic Approach}

Our method assumes that observed inventory behavior represents the industry's optimal actions given the available information. More specifically, we will be assuming that each industry solves a stochastic control problem. The objective is to maximize expected discounted net revenues. There are two controls: the rate of production and the rate at which raw materials are received. Sales are treated as exogenous, and are assumed to follow a known stochastic process. Therefore, with the passage of time, observations of sales alter the industries' beliefs about future sales.

We are interested in using observations of sales, production and deliveries of materials to infer the structure of adjustment costs that are fundamental determinants of the system. We first show how the optimal controls depend upon these unobserved parameters. Thus we use the empirically observed behavior to reconstruct what they must have been.

This model is grounded in a particular view about the use of inventory stocks to smooth out the activities of the firm over time. We imagine that the inventory adjustment process is somewhat "intermediate-run" in nature. In principal, a divergence of inventories from desired values could be mitigated by adjustments of a longer run nature, such as planned fixed investment, or of a shorter-run nature, such as cash management of the industry." Prices $^{\star \star}$ could also be varied. All these possibilities are ruled out; by assumption production and deliveries are assumed to be the only elements in the industries' plans that are responsive to undesirable inventory levels.

Caves, Jarrett and Loucks (1979) take an approach like this and relate the flexibility of the firm's operations to seller concentration at the 3-digit industry level.

** And likewise advertising and all other potential manipulators of demand. 
A second aspect of the "intermediate-run" nature of these responses relates to our empirical method. The data are quarterly. Information about sales and inventories is surely available to plant managers on a more frequent basis than that. We will be implicitly viewing the quarter to quarter responses as the optimizing values. If much faster adjustment were possible, and if information could be utilized much more quickly, our data would not correctly describe the workings of the system. On the other hand, if information were not received and processed within one quarter, our presumption that the industry is responding optimally given all lagged observations would be erroneous. "While we have no evidence to bring to bear at all, one quarter seems about right with respect to both of these considerations.

Because our data are at the industry level, it is appropriate to measure sales and inventories relative to capacity, or trend. The idea is that it is departures above or below the trend that cause costs to depart from their theoretical minimum values. These values could never really be maintained, being acheived only in the dealized state of smooth steady growth of capacity matched by a corresponding non-stochastic evolution of demand.

In each industry we have data on sales and on inventories in three stages, finished goods, work in process and materials. Each of these series are detrended separately. ${ }^{*}$ The reason for this is that the idealized cost minimizing levels may not be following precisely the same patterns of growth. For example, as new plants in the industry are brought "on line" and old ones are "retired" the optimal level of inventories relative to production may not

This may seem farfetched at the plant level, but if different firms within an industry face similar market conditions and if they are imperfectly informed about each other's status, then we may be closer to this danger at the industry level.

${ }^{\star *}$ We tried various specifications, these are described in section 9. 
remain constant. An equally important example is the evolution of superior inventory management techniques, often accelerated by the computer. These are exogenous to our study in that they are assumed to affect the optimal inventories relative to sales, but not the quarter to quarter movements relative to this level.*

Production should, in principle, be separated into two distinct activities: the act of taking materials and converting them into work in process, and the act of taking work in process and converting it into finished goods, either for immediate sale or addition to stocks. Such a system seemed to be too complex, so we have taken a pair of similar approaches. In the first one, which we will call the $\underline{\mathrm{WP}}$ system, materials stocks are ignored. What we will cal1 "production" in this system is the act of converting work in process (WP) into output. "Deliveries" of inputs are to be understood as the act of putting goods in the (WP) stage. Within this formalization therefore, we cannot distinguish between "true deliveries" from outside the industry and "deliveries" that describe the initiation of work on materials previously held as stocks within the industry.

The second approach identifies deliveries as the inputs that enter from outside the industry, efther into stocks of materials or work in process. We simply sum up these two series, calling the composite WM. In this system production is defined as taking $W M$ and converting it into finished output.

In the empirical section of the paper, we present estimates for only the WM system.

To the extent that this factor has influenced the structure of costs of adjustment as well as the ideal cost minimizing levels our model is inadequate. These parameters, in real terms, are assumed to be constant. *: The results for the Wr nodel are available from the authors upon request. They are gualitatively stmilar. 
The same theoretical model underlies both the WP and WM systems.

The basic variables of this model, all deviations from trend levels, are denoted:

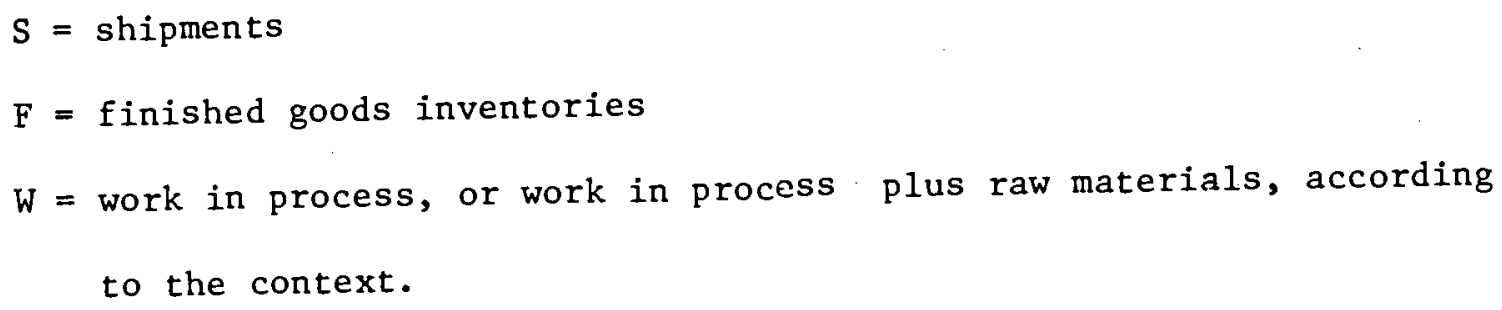

As mentioned above, there are two activities under the control of the decision-maker, production (P) and receiving deliveries (D). In our model it is perfectly possible that the same physical goods are received as deliveries and sold as output entirely within one quarter. We do not place any restrictions on the intensity with which the $P$ and $D$ activities can be operated; in particular their values are not constrained by the beginning of quarter levels of the stocks of work in process and materials. Stock-outs are not regarded as a problem, since all variables are deviations around trend; $P$ and D can be negative while actual producion is continually undertaken. We take $S$ to be exogenous. As there are no unfilled orders, it is assumed that all shipments are made immediately out of stocks. The value of $\mathrm{S}$ together with the choice of $\mathrm{P}$ and $\mathrm{D}$ determines the changes in the stocks of inventories; and thus, over time, the evolution of the entire system. 


\section{Types of Costs}

Our theoretical model utilizes a continuous time structure even though observations are made at discrete intervals. This is purely because a discrete time version of the optimization problem would have been much more complicated, and well beyond analytical tractibility. Our approach can perhaps be defended as an approximation.

We have the identities

$$
\begin{aligned}
& \dot{\mathrm{F}} \equiv \mathrm{P}-\mathrm{S} \\
& \dot{\mathrm{W}} \equiv \mathrm{D}-\mathrm{P}=\mathrm{D}-\dot{\mathrm{F}}-\mathrm{S}
\end{aligned}
$$

where all variables are measured in physical terms -- that is, in units of equivalent final output. The data are in terms of the value of the goods. However, as long as the share of value added at each stage of the process is a constant, the neglect of value added will not affect our results.

It will be convenient for us to use $\dot{F}$ and $\dot{W}$ as the decision variables rather than $\dot{\mathrm{P}}$ and $\dot{\mathrm{D}}$, so these identities are equivalently the definitions of $\mathrm{P}$ and $\mathrm{D}$ in terms of $\mathrm{S}, \dot{\mathrm{F}}$ and $\dot{\mathrm{W}}$,

$$
\begin{aligned}
& \mathrm{P} \equiv \mathrm{S}+\dot{\mathrm{F}} \\
& \mathrm{D} \equiv \mathrm{S}+\dot{\mathrm{F}}+\dot{\mathrm{W}}
\end{aligned}
$$

Notice that these definitions allow an increment in $S$ to be instantaneously accomodated with no change in inventories by an equal simultaneous increase in $P$ and $D$.

We take four kinds of costs into account: production, deliveries, and holding the two kinds of inventories. Each of these costs is assumed to be quadratic. We will also allow for a quadratic "interaction" term between 
holding the two kinds of inventories. Trend levels, if tracked exactly, are assumed to result in the least-cost method of production. Operating the basic activities, or holding the stocks, at levels above trend entails the use of less efficient techniques, for example overtime labor, supplies of materials that do not exactly match normal specifications, or less easily accessible storage locations. Operating below trend saves resources, but for the usual reasons these economies are iimited by returns to scale considerations.

In addition to quadratic terms in the deviations from trend levels, we can also consider quadratic terms in the rates of change of these four variables. It may be more expensive to be alternatively above and below trend than to remain above trend by a fixed amount for some time, and then steadily below trend for an equal interval. Costs of this type include labor force adjustment costs, costs of seeking out new sources of supply which will not be used on a steady basis, or the higher prices which might be charged by a usual source to whom a steady commitment for orders (implicit or explicit) is not made. Similarly quadratic terms in the rates of change of inventories represent the costs of putting goods in or taking them out.

There are two reasons for allowing an interaction between inventory levels, but not elsewhere. First, economically, we envision production, deliveries and storage as separate activities and so no interactions are allowed between them. The two kinds of storage may share facilities or equipment and therefore we might imagine, for example, that the marginal cost of holding extra finished goods is higher if a larger amount of work in process is preempting the most easily accessible storage space. 
Our second reason is more practical. Were more interaction terms allowed the model would be underidentified. But if the interaction between the two inventory holding costs were omitted from the specification, an additional complex, highly non-linear, constraint on the parameters would have been introduced. Overidentifying restrictions of this type would have rendered estimation impossible. The specification we did use imposes a single linear cross-equation restriction."

The quadratic nature of costs is necessary in our approach for a technical but very important reason. The stochastic dynamic programming problem whose solution we assume governs observed behavior is solved by looking at the "certainty-equivalent" problem -- that is the deterministic program in which all disturbances have been set equal to zero. We utilize the principle of "first-period-certainty-equivalence" which will be discussed in much more detail below. This principle is valid only when the objective is quadratic, and the equations of motion are linear ${ }^{* *}$, in the states and controls. Quadratic costs can of course be viewed as an approximation to more general functions, but other equally valid approximations would not have this certainty-equivalence property. On the other hand, there seems to be little hope for any practical alternative.

Summarizing this discussion we can write the instantaneous cost of operating at levels $\mathrm{P}$ and $\mathrm{D}$ as

\footnotetext{
* See below, equations (7.7) in section 7 and (8.2) in section 8. ** We will discuss the equations of motion in more detail shortly.
} 


$$
\begin{aligned}
& b_{0} P+b_{1} P^{2}+b_{2} \dot{P}^{2} \\
& \quad+m_{0} D+m_{1} D^{2}+m_{2} \dot{D}^{2} \\
& +h_{o} F+h_{1} F^{2}+h_{2} \dot{F}^{2} \\
& +g_{0} W+g_{1} W^{2}+g_{2} \dot{W}^{2}+k_{1} F W
\end{aligned}
$$

In some parts of the paper quadratic terms in rates of change are not used and we can just set $b_{2}=m_{2}=h_{2}=g_{2}=0$. 


\section{Control Theory Applied}

The objective function in stochastic control theory is written as the minimization of an integral. In the present case, discounted profit maximization means minimizing the integral of $(4.2)$ minus shipments (S), a11 of which can depend on time, multiplied by $e^{-r t}$, where $r$ is the instantaneous discount rate. We will assume that $r$ is constant. Therefore, still neglecting uncertainty, we have from (4.2) and the identities (4.1), the objective function

$$
\begin{aligned}
\min \int_{0}^{\infty} e^{-r t} & \left\{b_{0}(S+\dot{F})+b_{1}(S+\dot{F})^{2}\right. \\
& +b_{2}(\dot{S}+\ddot{F})^{2}+m_{o}(S+\dot{F}+\dot{W}) \\
& +m_{1}(S+\dot{F}+\dot{W})^{2}+m_{2}(\dot{S}+\ddot{F}+\ddot{W})^{2} \\
& +h_{o} F+h_{1} F^{2}+h_{2} \dot{F}^{2} \\
& \left.+g_{o} W+g_{1} W^{2}+g_{2} \dot{W}^{2}+k_{1} F W-S\right\} d t
\end{aligned}
$$

We now describe the way in which the system evolves over time. Here our discussion must be divided into two parts since the choice of the control variables depends upon whether or not we admit costs that are quadratic in the rates of change of $D, P, F$, and $W$ in the objective. These differences are primarily formal; the same basic assumptions will be maintained.

Let us begin with the simpler problem where such costs of adjustment are absent. It is natural to take $S, F$ and $W$ as state variables since they define the initial conditions facing the industry at any moment. The control variables are $\dot{F}$ and $\dot{W}$. From any given initial levels of $S, F$ and $W$, and given any path which the exogenous future of $S$ will follow, the use of $\dot{F}$ and $\dot{W}$ can control the paths of $F$ and $W$, or, equivalently, of $P$ and $D$. 
In order to apply the first-period certainty equivalence principle we must insure that the evolution equations are linear. The assumptions used to guarantee this linearity and the relationship between these assumptions and the data are crucial elements of the anaiysis.

Because of linear terms in the objective it will be notationally convenient to add a constant " $I$ " to the list of the state variables. We thus denote the state variable vector as

$$
x=(1, S, F, W)^{\prime}
$$

and the control vector as

$$
\mathrm{u}=(\dot{\mathrm{F}}, \dot{\mathrm{W}})^{\prime}
$$

We want to write

$$
\dot{x}=H x+G u
$$

for some matrices of constants $H$ and $G$. It is clear that the only problem can arise with $\dot{\mathrm{S}}$ which is exogenous and therefore must be written as a function of 1 ts own level, $\mathrm{S}$, and perhaps the constant. Recall that all our state variables are deviations from trend. Therefore the constant can have no effect. We are left with only one possibility,

$$
\dot{S}=\delta S
$$

for some $\delta$. We assume $\delta<0$ to ensure that the system is not explosive. To summarize, under complete certainty $S$ is an exogenous function of time and is, in theory, arbitrary. But to apply the principle of first-period certainty 
equivalence it is necessary to assume that $S$ is a very special kind of function, namely a simple exponential return to trend.

The evolution equation (5.2) is fulfilled by the matrices

$$
\mathrm{H}=\left(\begin{array}{llll}
0 & 0 & 0 & 0 \\
0 & \delta & 0 & 0 \\
0 & 0 & 0 & 0 \\
0 & 0 & 0 & 0
\end{array}\right)
$$

$$
G=\left(\begin{array}{ll}
0 & 0 \\
0 & 0 \\
1 & 0 \\
0 & 1
\end{array}\right)
$$

We now turn to the more complicated model where costs are allowed to depend on rates of change. The specification of states and controls must be modified since quadratic terms in $\ddot{F}$ and $\ddot{W}$ enter the instantaneous objective. It is natura1 to regard these as the controls and take both inventories and their rates of change into the state vector. Initial values of al1 of the state variables will be necessary for the system to be we11defined.

Writing

$$
\begin{aligned}
& x=(1, s, F, W, \dot{F}, \dot{W}) \\
& u=(\ddot{F}, \ddot{W})
\end{aligned}
$$

and

$$
\dot{\mathrm{x}}=\mathrm{H} \mathrm{x}+\mathrm{G} \mathrm{u}
$$

we have 
$(5.4)$

$$
\mathrm{H}=\left(\begin{array}{llllll}
0 & 0 & 0 & 0 & 0 & 0 \\
0 & \delta & 0 & 0 & 0 & 0 \\
0 & 0 & 0 & 0 & 1 & 0 \\
0 & 0 & 0 & 0 & 0 & 1 \\
0 & 0 & 0 & 0 & 0 & 0 \\
0 & 0 & 0 & 0 & 0 & 0
\end{array}\right)
$$

$$
G=\left(\begin{array}{ll}
0 & 0 \\
0 & 0 \\
0 & 0 \\
0 & 0 \\
1 & 0 \\
0 & 1
\end{array}\right)
$$

As above, the second row in each matrix is a consequence of the exogeneity of $S$ and our necessity to maintain linearity in this evolution equation in order to apply the certainty-equivalence principle. 
6. First-Period Certainty Equivalence and the Sales Process

It is the raison d'être for our model that $S$ does not follow a known path. Uncertainty about the future of $\mathrm{S}$ is of two kinds. If the average level of $\mathrm{S}$ were a known function of time, there might still be fluctuations around it. In addition as we move through time some of the initial uncertainties about future values of $\mathrm{S}$ may be partially resolved. Thus the sequence of expected values of $\mathrm{S}$ will change as new information is gathered.

Both of these issues are dealt with in the principle of first-period certainty equivalence. ${ }^{*}$ If the objective is quadratic and the equations of motion are linear, the controls that maximize the objective when all random variables are set equal to their expected values at the initial date are the same as the controls that solve the full stochastic dynamic optimization problem.** (Of course, after the initial date the controls of the original certainty-equivalent problem bear no relation to those of the full optimization. One must write the new certainty equivalent problem and solve again. It is precisely the idea of first-period certainty equivalence that a sequence of simpler problems can be used to replace a single, but much harder, one.)

To make use of the thoery outlined above, we must have a stochastic process for sales that has its expected deviation from trend converging geometrically to zero. We now consider how such a situation could arise and

\footnotetext{
* We are greatly indebted to Richard Clarke for discussions on this point. ** If it is possible to learn about the uncertainties earlier, or more accurately, by varying the level of the controls then this principle does not apply. In our case this is not a problem since sales are completely exogenous.
} 
whether our data on sales could justify assuming such a process.

Our first idea did not fit the data well, but is nevertheless a useful point to begin describing the basic method. It is based on our desire to distinguish between permanent and temporary innovations in the salesprocess. Suppose that actual sales $\mathrm{S}_{\text {act }}$ are distributed around their permanent level $\mathrm{S}_{\text {perm }}$ (6.1) $\quad S_{\text {act, } t}=S_{\text {perm, } t}+\varepsilon_{t}$ where $\varepsilon_{t}$ is white noise, and that the underlying permanent component evolves according to

(6.2) $\quad S_{\text {perm, } t}=n S_{\text {perm, } t-1}+\delta_{t}$.

Only $\mathrm{s}_{\text {act }}$ is observed; the entire past history of $\mathrm{s}_{\text {act }}$ is used to form an estimate of $S_{\text {perm, }}$ and $n$. We w111 assume that $n$ is known precisely and is not itself part of the Baysian revision process. Residual uncertainty about $S_{\text {perm, } t}$ will always remain present. Given our unbiased estimate of $S_{\text {perm }}, t$ the sequence of expected future values of $\mathrm{S}_{\text {act }}$ does converge to zero exponentially, as required. Therefore, subject to the proviso that there are sufficiently many past values of $s_{\text {act }}$ for uncertainty about $n$ to have been eliminated, this model of the sales process would allow us to proceed with the application of control theory.

To test whether the data followed such a process we proceeded as follows: Lagging ( 6.1$)$ we find that (6.3) $\quad S_{t}=n S_{t-1}-\eta \varepsilon_{t-1}+u_{t}+\varepsilon_{t}$ ,This equation was estimated by ordinary least squares, and by the standard bias formula we have 


$$
\operatorname{plim} \hat{n}_{\text {OLS }}=n\left(1-\frac{\sigma_{\varepsilon}^{2}}{\sigma_{\varepsilon}^{2}+\frac{\sigma_{u}^{2}}{1-\eta^{2}}}\right)<n
$$

since $\varepsilon_{t-1}$ is correlated with $S_{t-1}$.

However $\mathrm{S}_{t-2}$ is not correlated with $\varepsilon_{t-1}$, and thus we can estimate (6.3) using $\mathrm{S}_{t-2}$ as an instrument. Here

$$
\operatorname{plim} \hat{n}_{\mathrm{TSLS}}=n \text {. }
$$

When this procedure was applied to all seven of our industries, we found that

$$
\operatorname{plim} \hat{n}_{\text {TSLS }}<\text { plim } \hat{n}_{\text {OLS }}
$$

contradicting our maintained hypotheses. Of course it could be the case that $\varepsilon_{t}$ is itself a moving average process. In this case the observed relationship could arise even though the temporary-permanent distinction and the autoregressive nature of $\mathrm{S}_{\text {perm }}$ are valid. We tried using further lagged values of $\mathrm{S}_{t}$ as instruments, but the loss of precision precluded any decisive test on this basis.

In light of this we tried another formulation, one which did not manifest the temporary vs. permanent distinction so sharply but nevertheless admits a similar interpretation. We fit the deviations from trend to an ARMA process of varying structure, seeking the most descriptive, statistically significant form. In three of our industries a second order autoregressive process ARMA $(2,0)$ clearly fit the data better than ARMA $(1,1)$. But for 
two of them, ARMA $(1,1)$ was at least as good, or better, and for two, ARMA $(1,0)$ fit best.

We will now show how the $(1,1)$ process gives rise to expected future values that converge to zero exponentially. It therefore gives rise to a certainty-equivalent problem of the form required in the previous section.

We have

$$
s_{t}=\phi S_{t-1}+u_{t}-\theta u_{t-1}
$$

so that expected sales at $t+1$ viewed from time $t$ is

$$
t S_{t+1}^{*}=\phi\left(S_{t}-\frac{\theta}{\phi} u_{t}\right)
$$

Further into the future,

$$
t s_{t+k}^{*}=\phi^{k-1}\left(s_{t+1}^{*}\right) \quad \text { for all } k \geqq 2
$$

Therefore the expected future sales sequence behaves precisely as required. To specify its initial value, however, one first must apply a correction to current sales based on the current moving average component. This is observable at $t$ because of the simplicity of the $(1,1)$ process:

$$
u_{t}=s_{t}-\phi s_{t-1}+\theta u_{t-1}
$$

Empirically, some initial period may not be useful since we don't know where to start the $u_{t}$ sequence. But setting $u=0$ for a period somewhat farther back into the future, a good approximation to $v_{t}$ can be obtained, and on this basis $t^{*}{ }_{t+k}^{*}$ can be computed.

Higher order processes are, in principle, possible to handle by the same method. However they would entail a higher dimensional state vector 
in the control theory application, and we did not, therefore, pursue this course for the industries that appeared to be $\operatorname{ARMA}(2,0)$. 
7. Solution of the Certainty Equivalent Mode1: No Adjustment Costs

We now return to the analysis of the certainty equivalent model under the hypotheses described above. In this section we present the case of no adjustment costs, and in the next section the more general cost function is analyzed. We will describe the optimal control for this problem. Then we will show how this solution imposes a constraint on the parameters of our estimating equations and how one can recover the underlying cost parameters from these estimates.

We write the instantaneous set cost function, whose integral is to be minimized, as a quadratic form in the states $x=(1, S, F, W)^{\prime}$ and controls $u=(\dot{\bar{r}}, \dot{W})^{\prime}$, with the following notation ${ }^{*}$

$$
(x, u)^{\prime}\left(\begin{array}{c:c}
A & \text { N } \\
\cdots & \cdots \\
N^{\prime} & B
\end{array}\right) \quad(x, u)
$$

where the submatrices $A, N$ and $B$ are of dimensions compatible with $x$ and $u$, as shown.

It is important to note in our problem that these matrices are timedependent because of the discount factor $e^{-r t}$.

Thus we have

$$
\mathrm{e}^{\mathrm{rt}} \mathrm{A}=\left(\begin{array}{cccc}
0 & -\frac{1-\mathrm{b}_{0}-\mathrm{m}_{0}}{2} & \frac{\mathrm{h}_{0}}{2} & \frac{\mathrm{g}_{0}}{2} \\
-\frac{1-\mathrm{b}_{0}-\mathrm{m}_{0}}{2} & \mathrm{~b}_{1}+\mathrm{m}_{1} & 0 & 0 \\
\frac{\mathrm{h}_{0}}{2} & 0 & \mathrm{~h}_{1} & \mathrm{k}_{1} \\
\frac{\mathrm{g}_{0}}{2} & 0 & 0 & \mathrm{~g}_{1}
\end{array}\right)
$$

\footnotetext{
We follow the solution of Bryson and Ho (1975), chapter 5, section 2, problem 4.
} 
$e^{r t \quad N=}\left(\begin{array}{cc}\frac{b_{0}+m_{0}}{2} & \frac{m_{0}}{2} \\ b_{1}+m_{1} & m_{1} \\ 0 & 0 \\ 0 & 0 \\ e^{r t} \quad B= & m_{1}+m_{1} \\ b_{1} & m_{1}\end{array}\right)$

The key feature of solutions to this type of control problem is the introduction of a matrix $\mathrm{T}$, which is used to define the optimal control implicitly. I is a time-dependent square matrix with the dimensionality of the state vector: $4 \times 4$ in the present case. It is known that $T$ satisfies the following matrix differential equation, called the Riccati equation.

$$
\dot{T}=-T H-H^{\prime} T^{\prime}+(T G+N) B^{-1}\left(N^{\prime}+G^{\prime} T^{\prime}\right)-A
$$

The optimal control is defined from $\mathrm{T}$ by

$$
u^{*}=-B^{-1}\left(N^{\prime}+G^{\prime} T^{\prime}\right) x
$$

Employing this method in our problem is made much simpler by two observations. First, if we choose $A$ and $B$ to be symmetric, then $T$ will be symmetric. This reduces the number of variables in the Riccati equation. Second, the stationarity of our problem insures that optimizing the coefficients of the state variables, $-B^{-1}\left(H^{\prime} T+N^{\prime}\right)$, are not time dependent. Thus we know that, as a function of time, $T(t)=T e^{-r t}$ for some fixed matrix $T$, and hence in the 
Riccati equation we can write the left hand side as $-r T$, evaluating at $t=0$. This converts the Riccati equation to a system of polynomial (quadratic) equations for the unknown elements of $T$, rather than a system of differential equations for unknown functions of time.

Applying this method in our problem we find that the controls ${ }^{*}$ are given by:

$$
\alpha_{F S}=-\frac{1}{b_{1}}\left(T_{23}-T_{24}\right)-1
$$

$$
\alpha_{W S}=\frac{1}{b_{1}}\left(T_{23}-T_{24}\right)
$$

$$
a_{F F}=-\frac{1}{b_{1}}\left(T_{33}-T_{34}\right)
$$

$$
\alpha_{W F}=\frac{1}{b_{1}}\left(T_{33}-T_{34}\right)-\frac{1}{m_{1}} T_{34}
$$

$$
\alpha_{F W}=-\frac{i}{b_{1}}\left(T_{34}-T_{44}\right)
$$

$$
\alpha_{W W}^{:}=\frac{1}{b_{1}}\left(T_{34}-T_{44}\right)-\frac{1}{m_{1}} T_{44}
$$

where the first subscript (F or $W$ ) denotes the control ( $\dot{F}$ or $\dot{W}$ ). and the second subscript ( $S, F$ or $W$ ) denotes the state variable being considered.

\footnotetext{
*
}

We do not present the constant terms in the controls because our method in the empirical section works with detrended data (see above section 3 ). This amounts to choosing a reparameterization of the linear terms $b_{0}, m_{0}, g_{0}, h_{0}$ necessarily zero. 
The Riccati equations are ${ }^{* *}$

$$
\begin{aligned}
& (7.22)-\mathrm{rT}_{22}=-2 \delta \mathrm{T}_{22}-\left(\mathrm{T}_{23}+\mathrm{b}_{1}+\mathrm{m}_{1}\right) \alpha_{F S}-\left(\mathrm{T}_{24}-\mathrm{m}_{1}\right) \alpha_{W S}-\left(\mathrm{b}_{1}+\mathrm{m}_{1}\right) \\
& (7.23)-\mathrm{rT}_{23}=-\delta \mathrm{T}_{23}-\left(\mathrm{T}_{23}+\mathrm{b}_{1}+\mathrm{m}_{1}\right) \alpha_{F F}-\left(\mathrm{T}_{24}+\mathrm{m}_{1}\right) \alpha_{W F} \\
& (7.24)-\mathrm{rT}_{24}=-\delta \mathrm{T}_{24}-\left(\mathrm{T}_{23}+\mathrm{b}_{1}+\mathrm{m}_{1}\right) \alpha_{F W}-\left(\mathrm{T}_{24}+\mathrm{m}_{1}\right) \alpha_{W W} \\
& \text { (7.33) }-\mathrm{rT}_{33}=-\mathrm{T}_{33} \alpha_{F F}-\mathrm{T}_{34} \alpha_{W F}-\mathrm{h}_{1} \\
& \text { (7.34) }-\mathrm{rT}_{34}=-\mathrm{T}_{33} \alpha_{F W}-\mathrm{T}_{34} \alpha_{W W}-\mathrm{k}_{1} \\
& \text { (7.44) }-\mathrm{rT}_{44}=-\mathrm{T}_{34} \alpha_{F W}-\mathrm{T}_{44} \alpha_{W W}-\mathrm{g}_{1}
\end{aligned}
$$

Let us note, first of all, that there are 6 observable $\alpha$ 's, and 6 underlying parameters to be estimated $b_{1}, m_{1}, g_{1}, h_{1}, k_{1}$ and $r$. The value of $p$ is assumed to be known with certainty from the estimation of the ARMA sales process as described above. There àre, in addition, 6 auxilliary variables $\mathrm{T}_{22}, \mathrm{~T}_{23}, \mathrm{~T}_{24}, \mathrm{~T}_{33}, \mathrm{~T}_{34}$ and $\mathrm{T}_{44}$, and 6 Riccati equations that govern them. A priori the case for exact identification looks good.

However, examining the system of 12 equations, and dividing each of them by $b_{1}$, we see that $b_{1}$ can be eliminated. The underlying parameters of the system are really, $\mathrm{m}_{1} / \mathrm{b}_{1}, \mathrm{~g}_{1} / \mathrm{b}_{1}, \mathrm{~h}_{1} / \mathrm{b}_{1}, \mathrm{k}_{1} / \mathrm{b}_{1}, \mathrm{r}$ and the ratio of the six $\mathrm{T}^{\prime} \mathrm{s}$ to $b_{1}$. Correspondingly there is one overidentifying restriction imposed by the mode1. From $(7.1)$ and $(7.2)$ we see that

* Again, those involving the constant are not shown; they form an entirely separate subsystem.

** These equations are numbered mnenonically to facilitate future reference. 
(7.7) $\quad \alpha_{F S}+\alpha_{W S}=-1$.

To recover the 5 underlying parameters from estimated values of the $\alpha^{\prime} s$ that are constrained to satisfy $(7.7)$ we can use the following procedure:

i) From the estimates of $\alpha_{F F}, \alpha_{W E}, \alpha_{F W}$ and $\alpha_{W W}$ we can solve for $\frac{\mathrm{T}_{33}}{\mathrm{~b}_{1}}, \frac{\mathrm{T}_{34}}{\mathrm{~b}_{1}}, \frac{\mathrm{T}_{44}}{\mathrm{~b}_{1}}$, and $\frac{\mathrm{m}_{1}}{\mathrm{~b}_{1}}$

ii) Dividing the Riccati equations (7.33), (7.34) and (7.44) by $b_{1}$ we can substitute in from step 1 ) and solve for $\frac{h_{1}}{b_{1}}, \frac{k_{1}}{b_{1}}, \frac{g_{1}}{b_{1}}$, as linear functions of $r$, which is retained as a variable at this stage.

iii) Solve the pair of stationarity conditions (7.23) and (7.24) for $\frac{\mathrm{T}_{23}}{\mathrm{~b}_{1}}$ and $\frac{\mathrm{T}_{24}}{\mathrm{~b}_{1}}$ as functions of $\mathrm{r}$.

iv) Use the reduced form equation for $\alpha_{W S}$ and the results of step iii) to solve for $r$, and compute $\frac{\mathrm{T}_{23}}{\mathrm{~b}_{1}}$ and $\frac{\mathrm{T}_{24}}{\mathrm{~b}_{1}}$.

v) The value of $\mathrm{T}_{22}$ can be obtained from (7.22) using the results of step iv), but it is not really needed.

Note that in this procedure we did not use the reduced form for $\alpha_{F S}$ anywhere, its value being constrained in the estimation. All the other equations are satisfied by construction of our solution. 


\section{Solution of the Certainty Equivalent Model: Adjustment Costs}

In this section we give a brief description of the more general model. The basic method is exactly the same as that in the previous section, but there are several differences in the recovery of the parameters and in the constraint on the controls that the theory imposes.

The state vector is $x=(1, S, F, W, \dot{F}, \dot{W})^{\prime}$ and the controls are $u=(\ddot{F}, \ddot{W})^{\prime}$. The $A, B$ and $N$ matrices are now

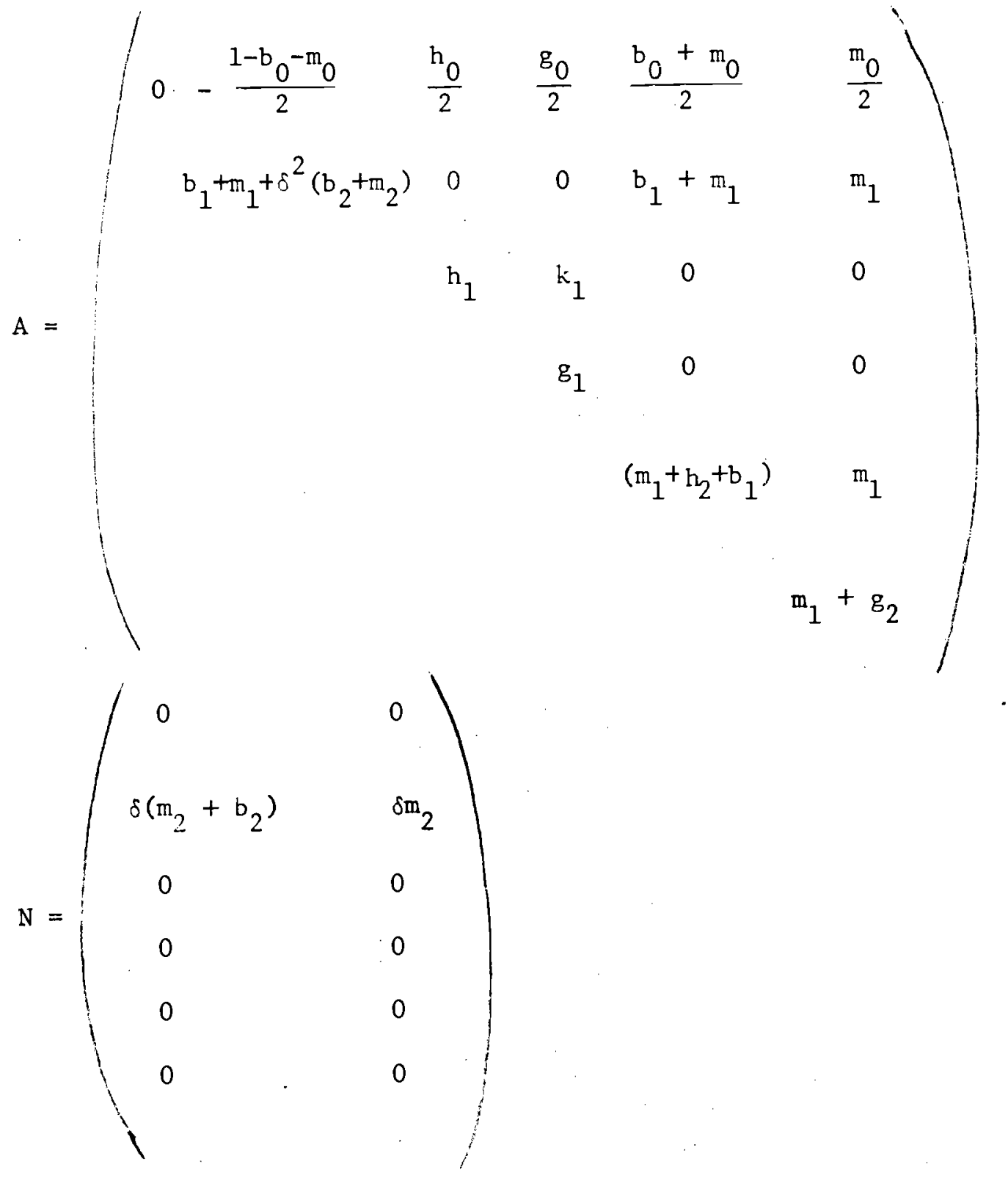

* $\mathrm{A}$ and $\mathrm{B}$ being symmetric, only the upper triangular matrix is shown. 


$$
\mathrm{B}=\left(\begin{array}{ll}
\mathrm{b}_{2}+\mathrm{m}_{2} & \mathrm{~m}_{2} \\
& \mathrm{~m}_{2}
\end{array}\right)
$$

The optimal controls are given by

$$
\begin{aligned}
& \left(\begin{array}{c}
\ddot{\mathrm{F}} \\
\ddot{\mathrm{W}}
\end{array} \mid \begin{array}{ccc}
-\frac{1}{\mathrm{~b}_{2}}\left(\mathrm{~T}_{51}-\mathrm{T}_{61}\right) & -\frac{1}{\mathrm{~b}_{2}}\left(\mathrm{~T}_{52}-\mathrm{T}_{62}\right)-\delta & -\frac{1}{\mathrm{~b}_{2}}\left(\mathrm{~T}_{5 i}-\mathrm{T}_{6 i}\right) \\
\frac{1}{\mathrm{~b}_{2}}\left(\mathrm{~T}_{51}-\mathrm{T}_{61}\right)-\frac{1}{\mathrm{~m}_{2}} \mathrm{~T}_{61} & \frac{1}{\mathrm{~b}_{2}}\left(\mathrm{~T}_{52}-\mathrm{T}_{62}\right) & \frac{1}{\mathrm{~b}_{2}}\left(\mathrm{~T}_{5 i}-\mathrm{T}_{6 i}\right)-\frac{1}{\mathrm{~m}_{2}} \mathrm{~T}_{6 i}
\end{array}\right) \\
& i=3,4,5,6
\end{aligned}
$$

Note that now the constraint on the parameters is that

$$
\beta_{F S}+\beta_{W S}=-\delta
$$

whereas the simpler model had the corresponding coefficients summing up to -1. The reason for this is that the controls are now the second derivatives of inventories. This change is explained as follows. On impact, ${ }^{*} \dot{F}+\dot{W}$ goes down by "dt units" after a unit increase in $S$. But since $\dot{S}=\delta S$, in the next small interval of time it continues to fall by $(1+\delta) d t$. Thus the second derivative would be computed as $-\delta$.

\footnotetext{
This is not really rigorous because $\mathrm{S}$ cannot change by discrete jumps in a continuous time model.
} 
$-32-$

The Riccati equations ${ }^{*}$ are,

(8.22) $-\mathrm{rT}_{22}=-2 \delta \mathrm{T}_{22}-\beta_{\mathrm{FS}}\left(\mathrm{T}_{25}+\delta\left(\mathrm{b}_{2}+\mathrm{m}_{2}\right)\right)-\beta_{\mathrm{WS}}\left(\mathrm{T}_{26}+\delta \mathrm{m}_{2}\right)-\left(\mathrm{b}_{1}+\mathrm{m}_{1}\right)+\delta^{2}\left(\mathrm{~b}_{2}+\mathrm{m}_{2}\right)$

(8.23) $-\mathrm{rT}_{23}=-\delta \mathrm{T}_{23}-\beta_{\mathrm{FF}}\left(\mathrm{T}_{25}+\delta\left(\mathrm{b}_{2}+\mathrm{m}_{2}\right)\right)-\beta_{\mathrm{WF}}\left(\mathrm{T}_{26}+\delta \mathrm{m}_{2}\right)$

$(8.24)-\mathrm{rT}_{24}=-\delta \mathrm{T}_{24}-\beta_{\mathrm{FW}}\left(\mathrm{T}_{25}+\delta\left(\mathrm{b}_{2}+\mathrm{m}_{2}\right)\right)-\beta_{\mathrm{WW}}\left(\mathrm{T}_{26}+\delta \mathrm{m}_{2}\right)$

(8.25) $-\mathrm{rT}_{25}=-\delta \mathrm{T}_{25}-\mathrm{T}_{23}-\beta_{\mathrm{F} \dot{\mathrm{F}}}\left(\mathrm{T}_{25}+\delta\left(\mathrm{b}_{2}+\mathrm{m}_{2}\right)\right)-\beta_{\mathrm{WF}}\left(\mathrm{T}_{26}+\delta \mathrm{m}_{2}\right)-\left(\mathrm{b}_{1}+\mathrm{m}_{1}\right)$

(8.26) $-\mathrm{rT}_{26}=-\delta \mathrm{T}_{26}-\mathrm{T}_{24}-\beta_{\mathrm{FW}} \cdot\left(\mathrm{T}_{25}+\delta\left(\mathrm{b}_{2}+\mathrm{m}_{2}\right)\right)-\beta_{\mathrm{WW}}\left(\mathrm{T}_{26}+\delta \mathrm{m}_{2}\right)-\mathrm{m}_{1}$

(8.33) $-\mathrm{rT}_{33}=-\beta_{\mathrm{FF}} \mathrm{T}_{35}-\beta_{\mathrm{WF}} \mathrm{T}_{36}-\mathrm{h}_{1}$

(8.34) $-\mathrm{rT}_{34}=-\beta_{\mathrm{FW}} \mathrm{T}_{35}-\beta_{W W} \mathrm{~T}_{36}-\mathrm{k}_{1}$

(8.35) $-\mathrm{rT}_{35}=-\mathrm{T}_{33}-\beta_{\mathrm{FF}} \mathrm{T}_{35}-\beta_{\mathrm{WF}} \mathrm{T}_{36}$

(8.36) $-\mathrm{rT}_{36}=-\mathrm{T}_{34}-\beta_{F \dot{W}} \mathrm{~T}_{35}-\beta_{\mathrm{WW}} \mathrm{T}_{36}$

$(8.44)-\mathrm{rT}_{44}=-\beta_{F W} \mathrm{~T}_{45}-\beta_{W W} \mathrm{~T}_{46}-\mathrm{g}_{1}$

(8.45) $-\mathrm{rT}_{45}=-\mathrm{T}_{34}-\beta_{\mathrm{FF}} \mathrm{T}_{45}-\beta_{\mathrm{WF}} \mathrm{T}_{46}$

(8.46) $-\mathrm{rT}_{46}=-\mathrm{T}_{44}-\beta_{F W} \mathrm{~T}_{45}-\beta_{W \dot{W}} \mathrm{~T}_{46}$

Again, mnenonically numbered. 
(8.55) $-\mathrm{rT}_{55}=-2 \mathrm{~T}_{35}-\beta_{\mathrm{FF}} \mathrm{T}_{55}-\beta_{W F} \mathrm{~T}_{56}-\left(\mathrm{b}_{1}+\mathrm{m}_{1}+\mathrm{h}_{2}\right)$

(8.56) $-\mathrm{rT}_{56}=-\mathrm{T}_{45}-\mathrm{T}_{36}-\beta_{\mathrm{FW}} \mathrm{T}_{55}-\beta_{\mathrm{WW}} \mathrm{T}_{56}-\mathrm{m}_{1}$

(8.66) $-\mathrm{rT}_{66}=-2 \mathrm{~T}_{46}-\beta_{F W} \cdot \mathrm{T}_{56}-\beta_{W W} \cdot \mathrm{T}_{66}-\left(\mathrm{m}_{1}+\mathrm{g}_{2}\right)$

To recover the parameters from the estimated coefficients of the control equation we can proceed as follows:

i) Normalize by setting $b_{2}=1$.

ii) Use the reduced forms for $\beta_{F \dot{F}}, \beta_{F \dot{W}}, \beta_{W F}$ and $\beta_{W \dot{W}}$ to find $T_{55}, T_{56}$,

$\mathrm{T}_{66}$ and $\mathrm{m}_{2}$ paralleling the method of step $i$ ) of the previous section.

iii) Use the reduced forms of $\beta_{F F}, \beta_{F W},{ }_{W F}$ and $\beta_{W W}$ to find $T_{35}, T_{36}$,

$\mathrm{T}_{45}$ and $\mathrm{T}_{46^{\circ}}$

iv) Solve the Riccati equations (8.35) and (845) for $\mathrm{r}$ and $\mathrm{T}_{34}$ given

the results of previous steps. This is a pair of linear equations in these two unknowns.

v) Use $(8.35),(8.46),(8.34),(8.33)$ and $(8.44)$ to obtain, successively $\mathrm{T}_{33}, \mathrm{~T}_{44}, \mathrm{k}_{1}, \mathrm{~h}_{1}$ and $\mathrm{g}_{1}$.

vi) Use $(8.56),(8.66),(8.55)$ to get $m_{1}, g_{2}$, and $b_{1}+h_{2}$. Note that $b_{1}$ and $h_{2}$ are not separately identified at this stage.

vii) Use $(8.23),(8.24),(8.25)$ and (8.26) together with the estimated value of ${ }_{F}$ FS as a system of 5 equations in the 5 unknowns, $\mathrm{T}_{23}, \mathrm{~T}_{24}, \mathrm{~T}_{25}, \mathrm{~T}_{26}$ and $\mathrm{b}_{1}$. Note that this identifies $h_{2}$ as well.

viii) The remaining Riccati condition (8.22) determines $T_{22}$. 
While the foregoing procedure would, in principle, allow us to recover the model's structural parameters from its reduced form estimates, the solution is quite messy and does not allow a clear understanding of the relationship between the reduced form coefficients and the parameters of the underlying model. Such an understanding would be helpful, since most previous empirical work on the subject has started with the reduced form and estimated it directly. We would like to know what their previous reduced form estimates suggest about the firm's cost function, given the stochastic process describing sales.

Fortunately, if we focus on finished goods inventories for the moment, a simpler relationship between reduced form and structural parameters obtains. In particular, if we ignore the costs related to deliveries $\left(\mathrm{m}_{0}, \mathrm{~m}_{1}\right.$, and $\left.\mathrm{m}_{2}\right)$ and work-in-process inventory stocks $\left(g_{0}, g_{1}, g_{2}\right.$, and $\left.k_{1}\right)$ and, further, assume that there is no cost in changing production $\left(b_{2}=0\right)$, we obtain a model with $\dot{F}$ as the lone control variable with the state vector equal to $(1, S, F) . *$ It is a straightforward exercise to show that such a model leads to the following two equations relating the control, $\dot{F}$, to the state variables $S$ and $F$ :

$$
\begin{aligned}
& \alpha_{F S}=-\frac{1}{b_{1}+h_{2}} T_{23}-1 \\
& \alpha_{F F}=-\frac{1}{b_{1}+h_{2}} T_{33}
\end{aligned}
$$

where the matrix $T$ is defined as before. The Riccati equations are:

* This model is a special case of the model presented above without adjustment costs, except we allow for the presence of a positive cost of changing stocks of finished goods inventories $\left(h_{2}>0\right)$. 


$$
\begin{aligned}
& -r \mathrm{~T}_{22}=-2 \delta \mathrm{T}_{22}-\left(\mathrm{T}_{23}+\mathrm{b}_{1}\right) \alpha_{F S}-\mathrm{b}_{1} \\
& -\mathrm{rT}_{23}=-\delta \mathrm{T}_{23}-\left(\mathrm{T}_{23}+\mathrm{b}_{1}\right) \alpha_{F F} \\
& -r \mathrm{~T}_{22}=-\mathrm{T}_{33}{ }^{\alpha} \mathrm{FF}-\mathrm{h}_{1}
\end{aligned}
$$

From these relations, we obtain solutions for $\alpha_{F F}$ and $\alpha_{F S}$ :

$$
\begin{aligned}
& \alpha_{F F}=\frac{r-\sqrt{r^{2}+4\left(\frac{h_{1}}{b_{1}+h_{2}}\right)}}{2} * \\
& \alpha_{F S}=-\frac{(r-\delta)-\left(\frac{h_{2}}{b_{1}+h_{2}}\right) \alpha_{F F}}{(r-\delta)-\alpha_{F F}}
\end{aligned}
$$

There are a number of things to be seen right away. If $h_{1}=0$ so that there are no quadratic costs involved in holding inventories, $\alpha_{F F}=0$ and $\alpha_{F S}=-1$ : inventories are passive, activing entirely as a buffer stock. At the other extreme, as $h_{1}$ becomes large, $\alpha_{F F}$ increases in absolute value, and $\alpha_{F S}$ decreases: as being away from the target inventory level increases, inventory investment responds more quickly to an inventory stock disequilibrium, and production changes, as well as changes in $F$, are used to respond to anticipated increases in sales. The general effects of the parameters $r, \delta, b_{1}$, $h_{1}$ and $h_{2}$ on. $\alpha_{F S}$ and $\alpha_{F F}$ are shown in Table 2 .

\section{Table 2}

Sign of Effects of Parameters on Controls

\begin{tabular}{lcc}
$\theta$ & ${ }_{F S}^{\alpha}$ & $\frac{{ }^{\alpha}}{F F}$ \\
\cline { 2 - 3 } & - & + \\
$\delta$ & + & 0 \\
$b_{1}$ & + & + \\
$h_{1}$ & + & - \\
$h_{2}$ & + & +
\end{tabular}

$x$

We choose the negative root here. It is clear that the positive root cannot correspond to an optimal path, since it would give us $q_{F}>0$, in violation of 
Because this model is underidentified, it is impossible to recover any of the underlying structural parameters from the reduced form regressions. However, we can derive certain inequality restrictions. In particular, $\alpha_{F F}<0$, and $\alpha_{F S}<-\frac{(r-\delta)}{(r-\delta)-\alpha_{F F}}$. Our estimates of this simple model suggest that the second restriction will be violated unless $r$ is negative, given our estimates of $\delta, \alpha_{F S}$ and $\alpha_{F F}$. This certainly casts some doubt on whether such a model is sufficient to explain inventory behavior, and provides evidence that the richer structure introduced above is indeed necessary. 


\section{Empirical Methodology and Results}

Before estimating the linear decision rules for inventory behavior suggested by the discussion above, we must transform our data to conform to the assumptions of the model. Since our model is concerned with deviations from trend, our first task is that of detrending the data.

We need to preserve the identities relating inventories, sales, production and deliveries in the detrended data, hence we are limited to a procedure that estimates trends for each series and subtracts it from the original series thus obtaining the detrended version. Given this approach, there are many ways to estimate the trends; our experiments suggest that the particular estination method used is of minor importance. Our chosen detrending technique consists of regressing sales, finished goods stocks, and work-in-process stocks (for the "IP" version of the model) or the sum of work-in-process and materiais and supplies stocks (for the "WM" version) individually on a constant, time, and higher moments of time. ${ }^{*}$ These higher moments are included to pick up any non-linearities (as would be present if the underlying trend were exponential. rather than linear). To test the sensitivity of our results, we aiso detrended the inventory series by regressing them on the sales trend directly, rather than on the moments of time. The resulting regressions using these two sets of data are virtually identical, and only the first set is presented. Since we estimate time trends separately for each series, our procedure allows for advances in technology over time which induce changes in the long-run inventory-sales ratio or the composition of inventory stocks.

\footnotetext{
Actually a third degree polynomial was used.
} 
Having detrended the series, our next task is to determine for each industry the ARMA process best describing the evolution of its sales. A second order autoregressive process provides the best fit for three industries (Textiles - SIC \#22, Paper - SIC \#26, and Instruments - SIC \#38). For the remaining industries, sales appear to be either ARMA $(1,1)$ or just AR (1). The estimates of $\phi$ and $\theta$, the autoregressive and moving average parameters are listed in Table 3 .

\section{$\underline{\text { Table } 3}$}

$$
\text { ARMA Processes - Shipments }
$$

$$
s_{t}=\phi s_{t-1}+u_{t}-\theta v_{t-1}
$$

\section{Industry (SIC \#)}

Food (20)

Chemicals (28)

Rubber and Plastics (30)

Stone, Clay and Glass (32)

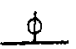

.61

.64

.84

.83

As discussed above, the sales term relevant for the certainty-equivalent problem of cost minimization, and hence the linear decision rules, is not $S_{t}$ but $S_{t}^{*}$, where

$$
\text { (9.1) } \quad S_{t}^{*}=S_{t}-\frac{\theta}{\phi} u_{t}
$$

The term $S_{t}^{*}$ may be thought of as the permanent component of sales, the temporary component being $S_{t}^{T}=\frac{\theta}{\phi} U_{t}$. This distinction is obviously of no relevance unles $\theta \neq 0$. For the two industries where sales do have a moving average component, it is important that we include $S^{*}$, and not $S$, in the final regressions. 
Given perfect knowledge of $\phi, \theta$ and all past realizations of sales, $u_{t}$ (and hence $\frac{\theta}{\phi} u_{t}$ ) may be calculated once $s_{t}$ is observed. This is precisely the behavioral assumption we apply to the firms themselves. In practice, our sample of S's is finite and $\phi$ and $\theta$ are estimated with error. Ignoring the latter problem, we can deal with the former one by assuming all values of $U_{t}$ to be zero prior to our first observation of sales, then recursively generating subsequent values of $U_{t}$ from (9.1) and finally omitting the first several such values. In practice, our first observation of sales is for the first quarter of 1958, and we have estimated our final regressions for the sample period $1960: 1$ to $1976: 4$.

In replacing $S_{t}$ with $S_{t}^{*}$ in our behavioral regressions, we must remember that actual sales in the current period are still $\mathrm{s}_{t}$, and some compensating adjustment for this must be made. Intuition suggests that an increase in temporary sales should be equivalent from the firm's viewpoint to a decline in initial stocks of finished goods, and indeed this proves to be true; in other words, the firm's costs depend on the sum of current sales and on the beginning of period stocks of finished goods. Holding future expectations constant an increase in current sales is indistinguishable from a drop in initial stocks. Thus, we can correctly represent the future sales expectations and at the same time account for the fact that current sales contain a temporary component by subtracting this component, $s_{t}^{T}=\frac{\theta}{\phi} U_{t}$, from initial finished goods inventories.

While our decision rules apply to a continuous time process, our data is quarterly. We approximate the above equations by setting the sales decay rate $-\delta$ equal to $(1-\phi)$, and replacing inventory stocks at time $t$ with the beginning of quarter stocks, $F_{t-1}$ and $W_{t-1}$. We represent the rates and rates of change of inventory investment by the first and second differences 
of these stocks, $\Delta F_{t}, \Delta \Delta F_{t}, \Delta W_{t}$ and $\Delta \Delta W_{t}$, respectively, where:

$$
\begin{aligned}
& \Delta I_{t}=I_{t}-I_{t-1} \\
& \Delta \Delta I_{t}=\Delta I_{t}-\Delta I_{t-1}
\end{aligned}
$$

With these approximations, the model in which adjustment costs are ignored is

$$
\Delta F_{t}=\alpha_{F S} S_{t}^{*}+\alpha_{F F} F_{t-1}^{*}+\alpha_{F W} W_{t-1}
$$

$$
\Delta W=\alpha_{W S} S_{t}^{*}+\alpha_{W} F_{t-1}^{*}+\alpha_{W W} W_{t-1}
$$

where $S_{t}^{*}=S_{t}-S_{t}^{T}$ and $F_{t-1}^{*}=F_{t-1}-S_{t}^{T}$, and the sum of $\alpha_{F S}$ and $\alpha_{W S}$ is constrained to equal -1 .

The model with adjustment costs is:

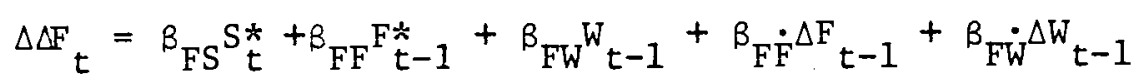

$(9.4)$

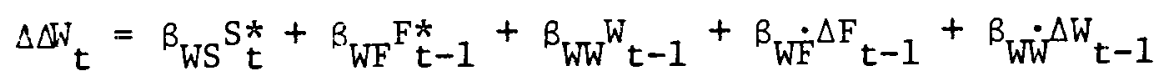

where $\beta_{F S}+\beta_{W S}=(1-\delta)$.

Note that no adjustment for $S_{t}^{T}$ is made to $\Delta F_{t-1}$. Such an adjustment would implicitly change the value of lagged production, and hence the cost of setting current production, which we would not want to do.

Also observe that, though the models with and without adjustment costs are nested in that setting the parameters by $b_{2}, m_{2}, g_{2}$ and $h_{2}$ in this model with adjustment costs equal to zero yields the simpler model, the discrete approximations we estimate are not nested. This follows from the different specification of the cross-equation constraint on the sales coefficients in the two models, and is a result of the approximation error involved in using discretely observed data to describe a continuous time process. 
In practice, of course, neither of these models will hold exactly, giving rise to a stochastic error term in each of the above regressions. This error term may be thought of as describing the failure of firms to successfully implement their intended production and delivery plans. Several explanations might be offered for such errors, ranging from the firm's own inability to perfectly monitor its own production activity to stochastic delivery behavior on the part of its suppliers. These errors need not be uncorrelated over time; for example, information about the errors being made may take more than a quarter to be completely discovered and corrected. Because of the presence of lagged dependent variables in our equations, we have estimated all regressions with a correction for first-order autocorrelation of the errors.

In order to test whether either of the models describes well the data we estimate equations $(9.3)$ and $(9.4)$ both with and without the implied cross-equation restrictions and test whether these restrictions can be accepted. In Tables 4,5,6 and 7 we present the results for the constrained and unconstrained versions of the models with and without adjustment costs. In all cases, we use the "WM" specification, where the stock of inventories $W$ is taken to be the sum of work-in-process and materials and supplies inventories.

A salient feature of our results is that the constraints on the sales coefficients do not seem to be satisfied. In all cases for the simpler model, the sum of $\alpha_{W S}$ and $\alpha_{F S}$ is significantly different from -1 (according to a likelihood ratio test), ranging between -.005 and .092 . The constraint is always rejected in the adjustment-cost model, though much less strongly.

*

We also performed these hypothesis tests on the constraints when corrections for heteroscedasticity are introduced. The F equation always contributed more to the SSR in the stacked regression than the $W$ equation. The equations were rithout significant changes in any coefficient or in the test statistic. 
Aside from the obvious explanation that the models may be misspecified, there remain other possible reasons for these negative results. First of all, our use of quarterly data to approximate a continuous time process may be inappropriate. Barring an attempt to rederive the model in a discrete-time framework (which would be very difficult) we might approach this problem by estimating the models using monthly data. At present, however, data of the same quality as ours is not available at monthly intervals. Another plausible explanation might be that the error process is not firstorder autoregressive. Again, this could be tested by using alternative specifications.

Despite our findings concerning the validity of these models, there are still a number of interesting results present in the regressions. Looking first at the unconstrained version of the simple model, where changes in inventories are regressed on lagged stocks and sales, we see that the implied adjustment speeds of changes to own stocks are large in comparison to those found by previous researchers. * For example, in SIC \#20 (Food), the coefficient of $\mathrm{F}_{-1}^{*}$ in the finished goods equation is -.558 , implying that $55 \%$ of a surplus in initial stocks of finished goods will be run down within a quarter. The corresponding coefficient for $W_{-1}$ in the $W$ regression is -.648 . These adjustment speeds are lower in SIC industries 非28 (Chemicals) and 非30 (Rubber and Plastics), but higher in SIC $\$ 32$ (Stone, Clay and Glass). Part of the explanation for these faster implied adjustment speeds may come from our use of detrended data. In addition, in contrast to many past studies, we have allowed for cross-effects in our regressions. We would expect these coefficients,

\footnotetext{
* For example Lovel1 (1961) and Auerbach-Feldstein (1976).
} 
of $\Delta \mathrm{F}$ on $\mathrm{W}_{-1}$ and $\Delta \mathrm{W}$ on $\mathrm{F}_{-1}^{*}$, to be positive: an unwarranted level of work-inprocess inventories can be partially lowered by stepping up production;

production can be lowered to reduce finished stocks, keeping more goods

"in the pipeline". Some evidence that such effects are present appears in these regressions. Six of the eight cross-effect terms in the four industries are positive, though only two are significant.

Turning to the more complicated model which includes adjustment costs, we continue to focus on the unconstrained estimates, in light of our rejection of the cross-equation constraints. Note that because the dependent variables are now $\Delta \Delta \mathrm{F}$ and $\Delta \Delta \mathrm{W}$, the assumption of the simpler model that lagged changes in stocks have no effect on current changes would imply that the coefficients of own changes equal -1 in the current regressions. In all four industries, at least one of the four lagged change terms introduced by the assumption of adjustment costs is significant. In all, seven of the sixteen new coefficients (in the four industries) are significant. Only the effect of lagged changes in $W$ on current changes in $F$ is never significant. This suggests that the richer specification is necessary to adequately model inventory behavior. 
Table 4

Estimated Decision Rules

("WM" Specification)

SIC 非20 (Food)

Model

No Adjustment Costs

Adjustment Costs

Constrained Unconstrained Constrained Unconstrained

Dependent Variable: $\underline{\Delta F} \quad \underline{\Delta W} \quad \underline{\Delta F} \quad \underline{\Delta W} \quad \underline{\Delta F} \quad \underline{\Delta W} \quad \underline{\Delta W} \quad \underline{\Delta} \quad \underline{W}$

Independent Variable:

$$
\begin{aligned}
& \text { S* } \quad-.464-.536^{*} \quad .074 \quad .018 \quad .232 \quad .158^{*}-.015 \quad .046^{*}
\end{aligned}
$$

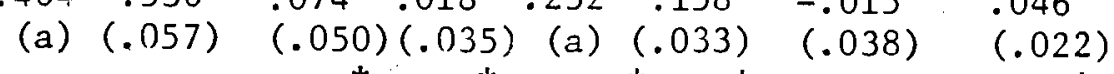

$$
\begin{aligned}
& \mathrm{F}_{-1}^{*} \quad-.313-.014-.558^{*} .237^{*}-.741^{*} .318^{*}-.195 \quad .116^{*} \\
& \begin{array}{llllll} 
& (.180)(.200) & (.218)(.092)(.166)(.117)(.105) & (.051) \\
W_{-1} & .235 & .092 & .115-.648^{*}-.058-1.074^{*}-.153 & -.496^{*}
\end{array}
\end{aligned}
$$

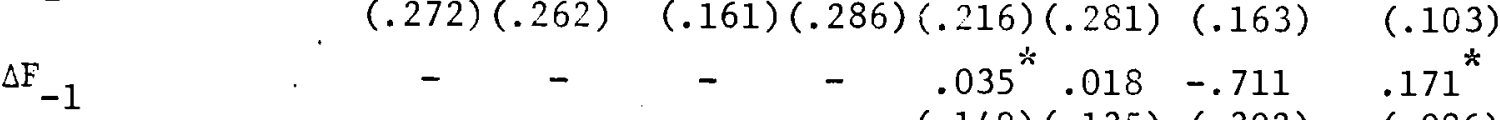

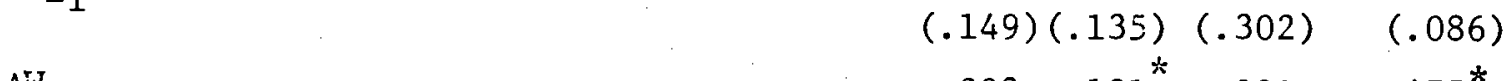

$$
\begin{aligned}
& \Delta \mathrm{W}_{-1} \quad \mathrm{*} \quad \mathrm{-} \quad \mathrm{-} .202-.121^{*} .291-.475^{*}
\end{aligned}
$$

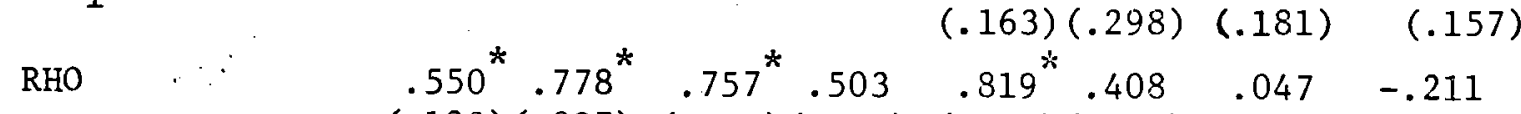

$$
\begin{aligned}
& (.122)(.097)(.157)(.269)(.077)(.210)(.377) \quad(.191) \\
& \mathrm{R}^{2}: \text { : } \quad \text { - } \quad .173 .247 \quad \text { - } \quad \text { - } .436 \quad .559 \\
& \text { SSR . } \quad \begin{array}{lllllll}
8.638^{\mathrm{b}} & 1.603 & .926 & 2.776^{\mathrm{b}} & 1.560 & .820
\end{array} \\
& \text { (standard errors in parentheses) } \\
& \text { * significant at .05 level } \\
& \text { a constrained parameter } \\
& \text { b from stacked regression }
\end{aligned}
$$




\author{
$\underline{\text { Table } 5}$ \\ Estimated Decision Rules \\ ("WM" Specification) \\ SIC \#28 (Chemicals)
}

Mode1

No Adjustment Costs

Constrained Unconstrained

Dependent Variable:

$\Delta \mathrm{F} \quad \Delta \mathrm{W}$

Independent Variable:

\section{Adjustment Costs}

Constrained Unconstrained

$\underline{\Delta W} \quad \underline{\Delta F} \quad \underline{\Delta \Delta W} \quad \underline{\Delta F} \quad \underline{\Delta U W}$

\begin{tabular}{|c|c|c|c|c|c|c|c|c|}
\hline$S^{*}$ & $\begin{array}{c}-.519 \\
\text { (a) }\end{array}$ & $\begin{array}{c}-.481^{*} \\
(.045)\end{array}$ & $\begin{array}{c}.007 \\
(.022)\end{array}$ & $\begin{array}{c}-.009 \\
(.021)\end{array}$ & $\begin{array}{r}.199 \\
\text { (a) }\end{array}$ & $\begin{array}{l}.161^{*} \\
(.025)\end{array}$ & $\begin{array}{c}.009 \\
(.013)\end{array}$ & $\begin{array}{c}-.000 \\
(.011)\end{array}$ \\
\hline$F_{-1}^{*}$ & $\begin{array}{l}.729^{*} \\
(.126)\end{array}$ & $\begin{array}{l}.615^{*} \\
(.127)\end{array}$ & $\begin{array}{l}-.122^{*} \\
(.052)\end{array}$ & $\begin{array}{l}.011 \\
(.048)\end{array}$ & $\begin{array}{l}-.441^{*} \\
(.075)\end{array}$ & $\begin{array}{l}-.226^{*} \\
(.074)\end{array}$ & $\begin{array}{l}-.123^{\star} \\
(.037)\end{array}$ & $\begin{array}{l}-.007 \\
(.030)\end{array}$ \\
\hline $\mathrm{W}_{-1}$ & $\begin{array}{l}-.115 \\
(.330)\end{array}$ & $\begin{array}{l}.440 \\
(.333)\end{array}$ & $\begin{array}{l}-.381^{\star} \\
(.115)\end{array}$ & $\begin{array}{c}-.449 \\
(.725)\end{array}$ & $\begin{array}{l}-.631^{*} \\
(.224)\end{array}$ & $\begin{array}{l}-1.050^{*} \\
(.232)\end{array}$ & $\begin{array}{l}-.252^{*} \\
(.103)\end{array}$ & $\frac{-.294^{*}}{(.077)}$ \\
\hline$\Delta F_{-1}$ & - & - & - & & $\begin{array}{c}-.140^{*} \\
(.185)\end{array}$ & $\begin{array}{c}-.097 \\
(.178)\end{array}$ & $\begin{array}{l}-.445^{2} \\
(.145)\end{array}$ & $\begin{array}{l}.027 \\
(.084)\end{array}$ \\
\hline$\Delta \mathrm{W}_{-1}$ & - & - & - & - & $\begin{array}{l}.303 \\
(.204)\end{array}$ & $\begin{array}{l}.169^{\star} \\
(.221)\end{array}$ & $\begin{array}{c}-.075 \\
(.142)\end{array}$ & $\begin{array}{c}-.319^{\star} \\
(.164)\end{array}$ \\
\hline RHO & $\left(.875^{*}\right.$ & $\begin{array}{l}.828^{*} \\
(.074)\end{array}$ & $\begin{array}{l}.459^{*} \\
(.123)\end{array}$ & $\begin{array}{c}.534 \\
(.725)\end{array}$ & $\begin{array}{l}.728^{*} \\
(.088)\end{array}$ & $\begin{array}{l}.735^{\star} \\
(.098)\end{array}$ & $\begin{array}{l}-.116 \\
(.203)\end{array}$ & $\begin{array}{c}-.290 \\
(.171)\end{array}$ \\
\hline$?^{2}$ & - & - & .366 & .208 & - & - & .415 & .431 \\
\hline סC & 2. & $11^{b}$ & .164 & .149 & 0.55 & & .1 .50 & .138 \\
\hline
\end{tabular}

(standard errors in parentheses)

* significant at .05 level

a constrained parameters

b from stacked regression 
Table 6

Estimated Decision Rules

("WM" Specification)

SIC $\# 30$ (Rubber and Plastics)

\section{Model}

No Adjustment Costs

Constrained Unconstrained

\section{Adjustment Costs}

Constrained Unconstrained

$\underline{\Delta F} \quad \underline{\Delta W} \quad \underline{\Delta F} \quad \underline{\Delta W} \quad \underline{\Delta F} \quad \underline{\Delta W} \quad \underline{\Delta F} \quad \underline{\Delta W}$

Dependent Variable:

Independent Variable:

$$
\begin{aligned}
& S^{*} \\
& -.526-.474^{*} .019 \\
& \begin{array}{lll}
(a) & (.051)(.019) \quad(.024)
\end{array} \\
& .083 \quad .077^{*} \quad .017 \\
& \text { (a) } \\
& (.022)(.020) \quad(.014) \\
& F * 1 \\
& \begin{array}{lll}
.447 \quad .425 & -.251
\end{array} \\
& (.314) \quad(.321)(.131) \\
& \begin{array}{lllll}
.078 & -1.08^{*} & .089 & -.211 & .056
\end{array} \\
& .178 * .859 * 0.1150 .299 * 0.146 *-.623 *-.091 *-.238 * \\
& W_{-1} \\
& .178 \quad .859^{*}-.115 \\
& (.298)(.075) \\
& \begin{array}{ccccc}
-.299 & -.146 & -.623^{*} & -.091 & -.238^{*} \\
(.231) & (.130) & (.132) & (.085) & (.050)
\end{array} \\
& \Delta \mathrm{F}_{-1} \\
& - \\
& \text { - } \quad \text { - } \quad \text { - } \quad .222^{*}-.164-.812-.098 \\
& -\quad-\quad- \\
& (.141) \quad(.135) \quad(.399) \quad(.118) \\
& \Delta W_{-1} \\
& \begin{array}{cccccccc}
.894^{*} & .997^{*} & .286 & .607^{*} & .852^{*} & .661^{*} & .105 & -.121 \\
(.074) & (.085) & (.213) & (.276) & (.063) & (.138) & (.535) & (.183)
\end{array} \\
& \overline{\mathrm{R}}^{2}
\end{aligned}
$$
* significant at .05 leve1
a constrained parameter
b from stacked regression 


\begin{abstract}
Table 7
Estimated Decision Rules

("WM" Specification)

SIC \#32 (Stone, Clay and Glass)
\end{abstract}

\title{
Mode1
}

No Adjustment Costs

Constrained Unconstrained

\section{Adjustment Costs}

Constrained Unconstrained

Dependent Variable:

$\underline{\Delta F}$

$\underline{\Delta W}$

$\underline{\mathrm{F}}$

$\underline{\Delta W}$

$\underline{\Delta \mathrm{F}}$

$\underline{\Delta \mathrm{W}} \quad \underline{\Delta \mathrm{F}}$

$\underline{\Delta \Delta}$

Independent Variable:

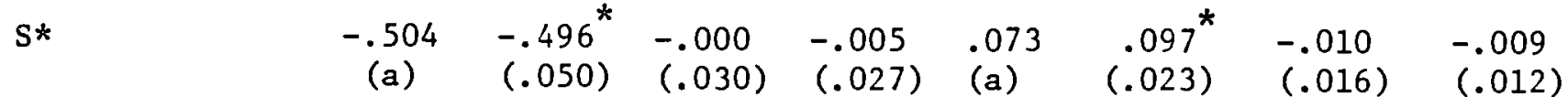

$$
\begin{aligned}
& F^{*}-1 \\
& \begin{array}{lllllll}
-.110 & .226 & -.850^{*} \quad .237^{*}-1.339^{*} & .406^{*} & -.485^{*} & -.033
\end{array} \\
& \begin{array}{lllllll}
(.228) & (.223)(.419)(.086) & (.248)(.179) \quad(.112) \quad(.075)
\end{array} \\
& \mathrm{W}_{-1}
\end{aligned}
$$

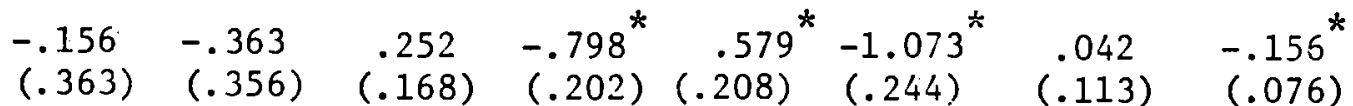

$$
\begin{aligned}
& \Delta \mathrm{F}_{-1} \\
& \begin{array}{rrrr}
-.073^{*}-.134 & -.570^{*} \quad .261^{*}
\end{array} \\
& \begin{array}{llll}
(.229)(.116) \quad(.157) \quad(.080)
\end{array} \\
& \Delta \mathrm{W}_{-1} \\
& \text { - } \quad \text { - } \quad \text { - } \quad \text { - }-0.225-.035^{*} \\
& \text { (.146) (.181) (.195) (.174) } \\
& \begin{array}{cccccccc}
.909^{*} & .955^{*} & .443 & .701^{*} & .533^{*} & .841^{* *} & -.288^{*} & -.319 \\
(.072) & (.075) & (.168) & (.180) & (.146) & (.082) & (.175) & (.181)
\end{array} \\
& \overline{\mathrm{R}}^{2} \\
& \begin{array}{lllllll}
- & - & .204 & .180 & - & &
\end{array} \\
& 0.465^{b} \\
& .062 \quad .027 \\
& 0.098^{b} \\
& .056
\end{aligned}
$$

\footnotetext{
* slgnificant at .05 level

a constrained parameter

b from stacked regression
} 
10. Conciusions

We have tried to give a structural account of inventory investment in manufacturing industries that produce to stock. Although our results must be viewed with caution because of technical problems such as the use of discrete data in estimating a continuous-time model, we still feel justified in asserting several results. First, the model with production adjustment costs obviously describes the data much better than without them. These previously neglected costs should be given a prominent role in future work. Second, disaggregating inventories by stage of fabrication we have seen how the interactions between production and deliveries give rise to important "feedback" and "feedforward" effects that are neglected in more aggregative analyses. Third, we have shown how a careful distinction between "temporary" and "permanent" innovations in sales can be important in the implementation of inventory investment models. 


\section{$\underline{\text { References }}$}

Abromovitz, Moses, "Inventories and Business Cycles," National Bureau of Economic Research, 1950.

Auerbach, Alan and Martin Feldstein, "Inventory Behavior in Durable-Goods Manufacturing: The Target-Adjustment Mode1," Brookings Papers on Economic Activity, 2, 1976.

Blinder, Alan S, and Stanley Fischer, "Inventories, Rational Expectations, and the Business Cycle," National Bureau of Economic Research Working Paper No. 381, August 1979.

Bryson, Arthur E. and Yu-Chi Ho, Applied Optimal Control, revised edition, Hemisphere Publishing, Washington, D.C., 1975.

Caves, Richard E., J. Peter Jarrett and Michael K. Loucks, "Competitive Conditions and the Firm's Buffer Stocks: An Exploratory Analysis," The Review of Economics and Statistics, Vol. LXI, No. 4, November 1979, pp. $485-496$.

Love11, Michae1, "Manufacturers' Inventories, Sales Expectations, and the Acceleration Principle," Econometrica, Vo1. 29, July 1961, pp. 293-314. Mack, Ruth P., "Information, Expectations, and Inventory Fluctuation: A Study of Materials Stock on Hand and on Order," New York: National Bureau of Economic Research, 1967.

Metzler, Lloyd A., "The Nature and Stability of Inventory Cycles," Review of Economic Statistics, Vo1. 23, August 1941, pp. 113-129. 